\title{
Electrochemical Study of the Copolymer Formation Between o-Chlorophenol and o-Hydroxyphenol
}

\author{
Said M. Sayyah ${ }^{\dagger, *}$, Said S. Abd-Elrehim ${ }^{\ddagger}$, Rehab E. Azooz ${ }^{\dagger, \&}$, and Fatma Mohamed ${ }^{\dagger}$ \\ ${ }^{\dagger}$ Polymer Research Laboratory, Chemistry Department, Faculty of Science, Beni-Suef University 62514, \\ Beni-Suef City, Egypt. "E-mail: smsayyah@hotmail.com \\ ${ }^{\ddagger}$ Chemistry Department, Faculty of Science, Ain Shams University, 11566 Abbassia, Cairo, Egypt \\ ${ }^{\S}$ Chemistry Department, Faculty of Science, Jazan University, 2097 Jazan, Saudi Arabia
}

(Received October 16, 2013; Accepted February 17, 2014)

\begin{abstract}
Electrochemical copolymerization of o-chlorophenol (oCP) with o-hydroxyphenol (oHP) was carried out in aqueous $\mathrm{H}_{2} \mathrm{SO}_{4}$ by using cyclic voltammetry $(\mathrm{CV})$ technique. In addition, $\mathrm{CV}$ was used to evaluate the differences in electrochemical characteristics of the copolymer in comparison with the corresponding homopolymers, poly(o-chlorophenol) (PoCP) and poly(o-hydroxyphenol) (PoHP). The variation of peak currents with respect to sweep rates was compared between copolymer and homopolymers, PoCP and PoHP, films. Further support for copolymer characterization was obtained by recording UV-visible, IR spectra and elemental analysis. The mechanism of the electrochemical polymerization has been discussed. The monomer reactivity ratios $\left(r_{1}\right.$ and $\left.r_{2}\right)$ were calculated using Fineman-Röss method and was found to be 0.4 and 1.3 repetitivelly and the copolymer structure is a block structure and more rich in oHP units.
\end{abstract}

Key words: Block copolymers, Electropolymerization, Reactivity ratios, Phenols

\section{INTRODUCTION}

Removal of phenol(s), Phs, from wastewater is of great importance due to their toxicity. ${ }^{1}$ Electrochemical oxidation is used for phenol(s) destruction intensively; however, it suffers from low reaction rates and low current efficiencies. ${ }^{2}$ The main reason for the low oxidation rate is electrode fouling and formation of tarry deposit as a result of anodic polymerization. ${ }^{3}$

Electropolymerization of Phs has been studied on different electrodes such as $\mathrm{Au},{ }^{4}$ glassy carbon, ${ }^{3} \mathrm{Pt}^{5},{ }^{5-11} \mathrm{PbO}_{2}{ }^{12}$ and BDD. ${ }^{13,14}$ From these investigations a mechanism is commonly accepted for phenol, $\mathrm{Ph}$, electropolymerization;, $, 8,11,15-18$ during the first step of oxidation, phenate anion gives rise to phenoxy radical, a phenoxy radical can react irreversibly with another radical or with an unreacted phenate anion via $\mathrm{C}-\mathrm{C}$ or $\mathrm{C}-\mathrm{O}$ coupling to form dimeric products. ${ }^{3,8,10,17-22}$ Such dimer can be oxidized again to produce a new radical which can couple with a phenoxy radical or with other dimeric radical to produce the polymer.

Tars formed by electropolymerization of phenol show low permeability and strong adhesion to the electrode, ${ }^{4,23}$ the rate of formation of tars depend on phenoxy radical concentration which can be limited by decreasing the concentration of phenol. Phenoxy radicals are responsible for the polymerization reaction and so the formation rate of tar will depend on their concentration and lifetime. The radical concentration can be limited by decreasing the concentration of phenol and minimizing the current density. Radical lifetime can be decreased by decreasing $\mathrm{pH}$ because the phenol oxidation potential decreases with $\mathrm{pH}$ while the phenoxy radical oxidation potential remains unchanged. Thus the ratio of the overpotentials and hence reaction rates will decrease with $\mathrm{pH}^{3}$

This film was considered to be composed of a tightly adsorbed layer of products of oxidation and polymerization covered with polymeric and oligomeric layers. ${ }^{24,25}$ The tightly adsorbed layer is unaffected by oxygen evolution while the upper layers can be disrupted by gas evolution. Therefore, oxygen evolution is beneficial to prevent complete deactivation of the electrode by a thick polymeric film; however, electron transfer remains hindered by a barrier at the electrode surface.

On the other hand, formation of polymer, occurring by direct electron transfer in the potential region of water stability, could be convenient in wastewater treatment with respect to energy consumption since less than two electrons is required per phenol molecule to trigger polymerization. ${ }^{17,21}$ The removal of some phenolic compounds from aqueous solutions based on electropolymerization was recently attempted. ${ }^{21,26-28}$ By this method phenol is immobilized as a solid polymer on the anode surface by electrolysis at a 
low anodic current density in neutral solution.

Non-conducting films prepared by electropolymerization method are also important. The resulting non-conducting film usually has a small thickness and is self-controlled by the increase in electrical resistance during its growth on the electrode. Because non-conducting polymers are always thin (10-100 nm), substrates and products can diffuse rapidly to and from the film modified electrodes. Therefore, fast response time and high selectivity could be expected for non-conducting polymer based electrochemical sensors. PoCP modified Pt electrode is used as a $\mathrm{pH}$ sensor with good response and perfect Nernstian-slope especially at $\mathrm{pH}$ range 4-9 but its poor $\mathrm{pH}$ sensor at more acidic or basic solution and loose its response by time. ${ }^{11}$ We think copolymerization may solve this problem.

In our previous work, ${ }^{11} \mathrm{PoCP}$ and $\mathrm{PoHP}$ were formed at $\mathrm{Pt}$ electrode from $\mathrm{H}_{2} \mathrm{SO}_{4}$ medium by electropolymerization; as almost all phenols they have a mostly similar behavior especially in responce time, formation of tars and the effect repetitive cycling.

In this work copolymerization of oCP with $\mathrm{OHP}$ in aqueous $\mathrm{H}_{2} \mathrm{SO}_{4}$ by using cyclic voltammetry $(\mathrm{CV})$ technique will be done which to the best of our kwnoldge was not studied in the literature before. In addition, CV will be used to evaluate the differences in electrochemical characteristics of the homo and copolymers. Tools as UV-visible and IR spectra will be used to study the copolymer formation and finally the mechanism of the electrochemical copolymerization reaction has been discussed.

\section{EXPERIMENTAL}

\section{Materials}

oCP was obtained from Hopkin \& Williams (Dagenham, Essex, UK), sulfuric acid was provided by Merck (Darmstadt, Germany) and oHP was provided by Aldrich (USA). All chemicals are of analytical pure grade and used as received. All solutions were prepared by using freshly double-distilled water.

\section{Electropolymerization Cell}

Electropolymerization of the monomers and formation of the polymer films was carried out using CV technique. The cell used is a home-made from transparent Prespex trough, which has the inside dimensions of $8 \mathrm{~cm}$ length, $2.5 \mathrm{~cm}$ width and $3 \mathrm{~cm}$ height.

\section{Electrodes}

\section{Working electrode}

The working electrode (WE) was a platinum sheet with dimensions of $1 \mathrm{~cm}$ length and $0.5 \mathrm{~cm}$ width

\section{Auxiliary electrode}

The auxiliary (counter) electrode (CE) was a platinum foil with the same dimensions as the WE. Before each run, both the WE and the CE were cleaned and washed thoroughly with water, double distilled water, rinsed with ethanol and dried.

\section{Reference electrode}

A saturated calomel electrode (SCE) was used as a reference electrode (RE). The values of the electrode potential in the present work are given relative to this electrode. The potential value for the SCE is $0.242 \mathrm{~V}$ vs NHE at $25^{\circ} \mathrm{C}$. SCE was periodically calibrated and checked.

Electrochemical experiments were performed using the Potentiostat/Galvanostat Wenking PGS 95. i-E curves were recorded by computer software from the same company (Model ECT). Except otherwise stated, the potential was swept linearly from starting potential into the positive direction up to a certain anodic potential with a given scan rate and then reversed with the same scan rate up to the starting cathodic potential.

For each run, freshly prepared solutions as well as a cleaned set of electrodes were used. All experiments were conducted at a given temperature $\left( \pm 0.5^{\circ} \mathrm{C}\right)$ with the help of circular water thermostat. After film formation, the WE was withdrawn from the cell, rinsed thoroughly with a doubly distilled water to remove any traces of the formed constituents in the reaction medium. The deposited polymer film was subjected to different experimental tests to characterize it.

\section{Procedure}

Potentiodynamic cyclic voltammetry measurements during the formation of the polymer and/or copolymer films on the surface of the WE was carried out in the electrochemical cell that filled with the test solution (aqueous solution containing $\mathrm{H}_{2} \mathrm{SO}_{4}$ as supporting electrolyte, and monomer). The WE and CE were introduced in the cell. The RE was attached to the cell by $\mathrm{U}$-shaped salt bridge (SB) ended with a fine capillary tip (Luggin-Harber probe) wherein the reference electrode was positioned much closed to the WE to minimize the over potential due to electrolyte resistance. The bridge was filled with the test solution. Before and during measurements a current of pure nitrogen gas was bubbled in the test solution, to remove dissolved oxygen.

\section{Characterization of the Formed Polymers \\ UV-visible, IR spectroscopy and Elemental analysis}


UV-visible absorption spectra of the prepared polymer sample was measured using Shimadzu UV spectrophotometer (M160 PC) at room temperature in the range 200$700 \mathrm{~nm}$ using dimethylformamide (DMF) as a solvent and reference. IR measurements were carried out using shimadzu FTIR-340 Jasco spectrophotometer (Japan) by KBr pellets disk technique. Elemental analysis was carried out in the micro-analytical center at Cairo University (Cairo, Egypt) by oxygen flask combustion and dosimat E415 titrator (Metrohm).

\section{RESULTS AND DISCUSSION}

\section{Electrochemical Copolymerization}

Fig. 1 represents the CVs recorded for the first cycle during the polymerization of a mixture of oCP and $\mathrm{oHP}$ with molar feed ratio kept at 1:1. For making a close comparison of the CVs during copolymerization with growth of oCP and oHP, electropolymerization of oCP and oHP was also performed under otherwise identical conditions to the copolymerization. The obtained voltammograms - at $+v e$ direction - in absence and presence of monomer is represented in Fig. 1.

Based on Fig. 1, The voltammogram in the absence of monomer exhibit no peaks. Oxidation potentials $\left(E_{p}{ }^{a}\right)$ of $\mathrm{oCP}$ and oHP is found to be at $0.86 \mathrm{~V}$ and $0.62 \mathrm{~V}$ respectivelly. ${ }^{11}$ Where that of the mixture of both is at $0.70 \mathrm{~V}$. Reduction potentials $\left(E_{p}{ }^{c}\right)$ of oCP and oHP is found to be at $(\sim 0.25 \mathrm{~V})$ and $(0.20 \mathrm{~V})$ respectively. ${ }^{11}$ Where no reduction peaks is observed for the mixture of $\mathrm{oCP}$ and $\mathrm{oHP}$ (1:1 molar ratio).

The data reveals that; the anodic oxidation peaks $\left(i_{p}{ }^{a}\right)$;

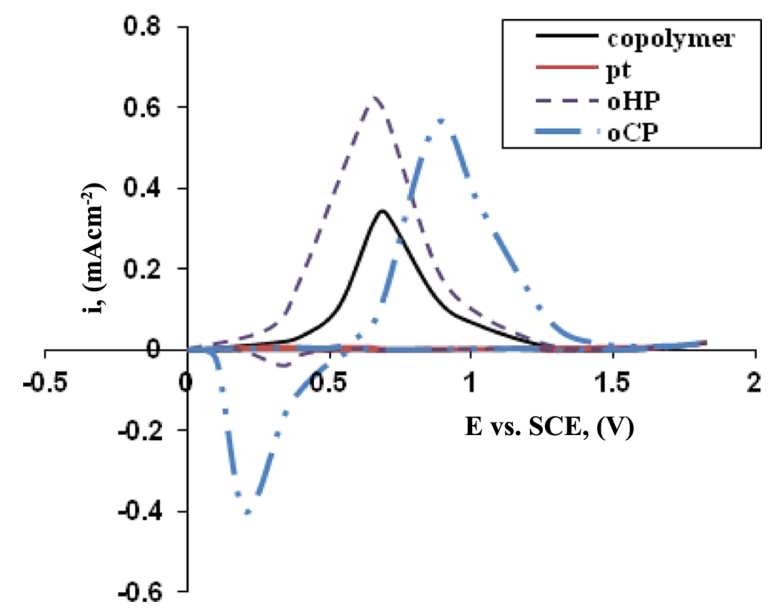

Figure 1. CV curves during electropolymerization of $\mathrm{Pt}$ in $0.6 \mathrm{M}$ $\mathrm{H}_{2} \mathrm{SO}_{4}$ with scan rate $25 \mathrm{mVs}^{-1}$ at $303 \mathrm{~K}$ in the absence or presence of; $0.08 \mathrm{M}$ oHP, $0.04 \mathrm{M}$ oCP or $0.05 \mathrm{M}$ of oHP and oCP [1:1 molar ratio]. are attributed to the removal of electron from oxygen atom of the hydroxyl group to form free radical in all cases which adsorbed on Pt-electrode. The adsorbed radicals react with other radical or monomer molecule at Pt surface via headto-tail coupling to form predominantly a para-linked dimeric radical and so on to form oligomer and polymer film; this film is a chain of isolated aromatic rings (polyethers) without $\pi$-electrons delocalization between each unit as shown in Schemes 1 and 2., ${ }^{70,11}$ The oxidation occurs at more positive values $\sim+0.86$ and $+0.62 \mathrm{mV}$ (vs SEC) for oHP and oCP repetitively, where the presence $(\mathrm{Cl}$ and $\mathrm{OH})$ make the oxidation process difficult compared with that of phenol - at + $0.55 \mathrm{mV}$ (vs SEC) -. It seems that electron donating groups $(\mathrm{Cl}$ and $\mathrm{OH})$ attached in ortho position to $\mathrm{OH}$ of phenol increase the acidity of compound and make the oxidation process difficult.

On reversing the potential scan from, the reversing anodic current is very small in all cases indicating the presence of polymer/copolymer layer adhered to the Pt-surface. ${ }^{11,29}$ One cathodic peak was found incase of oHP and oCP which could be ascribed to the reduction of the formed homopolymer films. The cathodic span of the reverse scan of the binary monomer mixture doesn't involve any cathodic peak indicating that the system is totally irreversible as a result

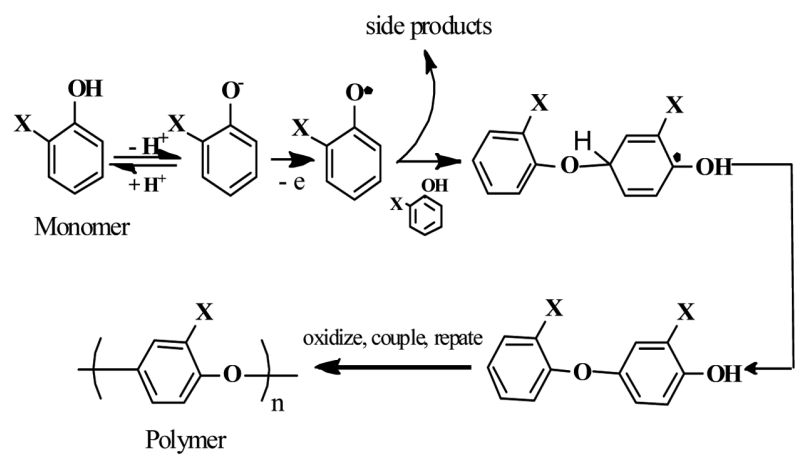

where, $\mathrm{X}=\mathrm{Cl}$ or $\mathrm{OH}$

Scheme 1. Oxidation of Phs to give Polymer.
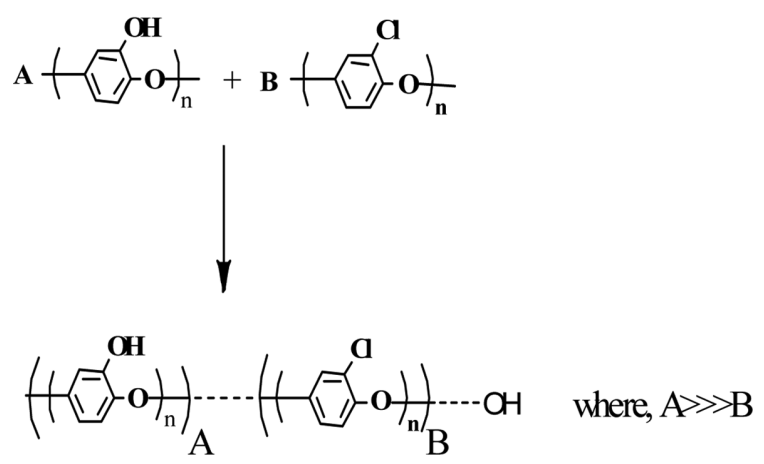

Scheme 2. Formation of $\mathrm{P}(\mathrm{oCP}-\mathrm{co}-\mathrm{oHP})$ block copolymer. 
of the strong adhession of the copolymer film to Pt surface, insulating property of the copolymer film no - electroactive species - and/or the nature and kind of oxide species formed on the Pt surface during the electrooxidation is the reson. ${ }^{30}$

When we try to use negative potentials in all cases we obtain only one oxidation peak corresponding to the adsorption of hydrogen on Pt-electrode in presence and absence of monomers which developed at $-300 \mathrm{mV}$ (vs SCE) ${ }^{31}$ this peak is omitted in all Figures for facilitate the comparison.

The above data confirm the formation of a copolymer film at $E_{p}{ }^{a} \sim 700 \mathrm{mV}$ (vs SCE) in between the potentials of the two separate homopolymers.

\section{Effect of Repetitive Cycling}

It is known that fouling of electrode may occurs during phenols oxidation where phenolic products block the electrode surface ${ }^{11,23,31}$ and the formed film hinders diffusion of further phenoxide ions to the electrode surface, thereby causing a significant decrease in the anodic peak current. ${ }^{32}$

The effect of repetitive cycling on the formation of the copolymer film on Pt-electrode surface from an aqueous solution containing $0.6 \mathrm{M} \mathrm{H}_{2} \mathrm{SO}_{4}, 0.05 \mathrm{M}$ comonomer (1:1) molar ratio at $303 \mathrm{~K}$ was done using $25 \mathrm{mVs}^{-1}$ as scan rate. The data reveals that the peak current densities $\left(i_{p}\right)$ decreases with repetitive cycling confirming the fouling of electrode and a formation of insulating and good adherent copolymer films on Pt-surface. Also this behavior is observed in the case of homopolymers formation.

Both $E_{p}{ }^{a}$ and $E_{p}{ }^{c}$ for PoHP and PoCP and $E_{p}{ }^{a}$ of the copolymer formation does not shift with increasing number of cycles, indicating that the oxidation and the reduction reactions are independent on the polymer thickness. ${ }^{29,32-34}$

\section{Effect of Scan Rate}

The influence of the scan rate $\left(15-40 \mathrm{mVs}^{-1}\right)$ on the potentiodynamic anodic polarization curves for $0.05 \mathrm{M}$ comonomer (1:1 molar ratio) from aqueous solution containing $0.6 \mathrm{M} \mathrm{H}_{2} \mathrm{SO}_{4}$ at $303 \mathrm{~K}$ on Platinum electrode is done. It is obvious that the anodic peak current densities $\left(i_{p I}\right)$ increases with the increasing of the scan rate. As seen in Fig. 2A. This behavior may be explained as follows, when an enough potential is applied at an electrode surface causing oxidation of species in solution, a current arises due to the depletion of the species in the vicinity of the electrode surface. As a consequence, a concentration gradient appears in the solution. The current $\left(i_{p}\right)$ is proportional to the gradient slope, $\mathrm{dc} / \mathrm{dx}$, imposed $(i=\mathrm{dc} / \mathrm{dx})$. As the scan rate increase
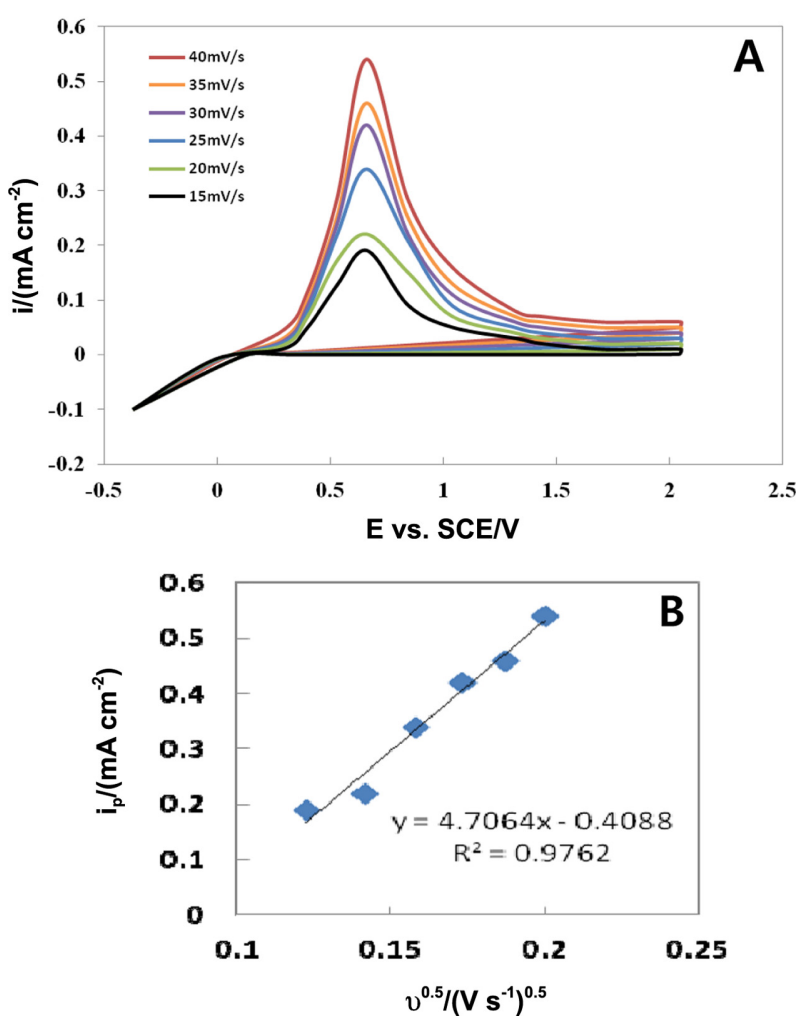

Figure 2. (A) CV at different scan rate (15, 20, 25, 30, 35 and $40 \mathrm{mV} / \mathrm{s}$ ): from solution containing $0.05 \mathrm{M}$ monomer (1:1 molar ratio) and $0.6 \mathrm{M} \mathrm{H}_{2} \mathrm{SO}_{4}$ at $303 \mathrm{~K}$ on Pt-electrode. (B) Relation between $i_{p}$ vs $v^{1 / 2}$.

the gradient increase and consequently the current $\left(i_{p}\right)$.

Fig. 2B shows the linear dependency of the anodic peak current density $\left(i_{p}\right)$ on the square root of scan rate $\left(v^{1 / 2}\right)$. This linear relation suggests that the oxidation of comonomer to copolymer may be described by a partially diffusioncontrolled process (diffusion of reacting species to the copolymer film/solution interface), ${ }_{11}^{11}$ where the correlation coefficients $\left(\mathrm{r}^{2}\right)$ is higher than 0.9 but not equal to 1.0 suggesting the non-ideal simulation relation (i.e., the process is not completely diffusion control but it is exactly a partially diffusion control.

Values of $i_{\mathrm{p}}$ are proportional directly to $v^{1 / 2}$ according to Randless $^{35}$ and Sevick ${ }^{36}$ equation;

$$
i_{p}=0.4463 n F A C \sqrt{\frac{c F v D}{R T}}
$$

Where $\mathrm{A}$ is electrode area in $\left(\mathrm{cm}^{2}\right), \mathrm{n}$ is the number of exchanged electron in the mechanism, $\mathrm{C}$ is the bulk concentration in $\left(\mathrm{mol} \mathrm{cm}^{-3}\right), \mathrm{D}$ is the diffusing coefficient in $\left(\mathrm{m}^{2} \mathrm{~s}^{-1}\right)$, and $v$ is the scan rate in $\left(\mathrm{Vs}^{-1}\right)$. The calculated values of $\mathrm{D}$ (at $0.6 \mathrm{M} \mathrm{H}_{2} \mathrm{SO}_{4}, 0.05 \mathrm{M}$ comonomer at $303 \mathrm{~K}$ with scan rate from $\left(15\right.$ to $\left.40 \mathrm{mV} \mathrm{s}^{-1}\right)$ are ranged from $5.7 \times 10^{-7}$ 
to $7.36 \times 10^{-7} \mathrm{~m}^{2} \mathrm{~s}^{-1}$;

For the homopolymer formation we found that $\mathrm{D}$ is almost constant; $\mathrm{D}_{\mathrm{oHP} \rightarrow \mathrm{PoHP}}$ ranged from $8.2 \times 10^{-11}$ to $1.16 \times 10^{-10} \mathrm{~m}^{2} \mathrm{~s}^{-1}$ and $\mathrm{D}_{\mathrm{oCP} \rightarrow \mathrm{PoCP}}$ ranged from $9.11 \times 10^{-11}$ to $1.18 \times 10^{-10} \mathrm{~m}^{2} \mathrm{~s}^{-1}$. The values of $\mathrm{D}$ are seen to be constant over the range of sweep rates, which again shows that the oxidation process is diffusion-controlled. ${ }^{31}$

Fig. 2(B) shows the linear dependence of the anodic current peak, $\left(i_{p I}\right)$ versus $v^{1 / 2}$ for copolymerization process. This linear regression equation was;

$$
i_{p}(\mathrm{~mA})=0.1192 \sqrt{v}\left(\frac{m V}{s}\right)^{1 / 2}-0.3085
$$

With a correlation coefficient of $r^{2}=0.92$. So we suggest that the electroformation of copolymer may be described partially by a diffusion-controlled process (diffusion of reacting species to the polymer film/solution interface). ${ }^{37-39}$ It seems that, initially the electroformation of radical cations controlled by charge transfer process. When the thickness of the polymer becomes thick, the diffusion of reactant inside the film becomes the slowest step, the process changed to diffusion transfer.

The intercept in Fig. 2B is small and negative, -0.3085 , which could be attributed to a decrease of the active area of the working electrode during the positive $\operatorname{scan}^{40}$ or the increase of the covered area of working electrode by the adhered copolymer sample.

For the two homopolymers, ${ }^{11}$ the linear regression equations are;

For oCP,

$$
i_{p}(m A)=0.207 \sqrt{v}\left(\frac{m V}{s}\right)^{1 / 2}-0.60 \quad \mathrm{r}^{2}=0.90
$$

For oHP,

$$
i_{p}(m A)=0.228 \sqrt{v}\left(\frac{m V}{s}\right)^{1 / 2}-0.53 \quad \mathrm{r}^{2}=0.99
$$

These data also confirm the same formation nature and the partially diffusion controlled process.

\section{Effect of the Electropolymerization Parameters Effect of comonomer concentration}

The influence of oCP, oHP and a mixture of both in a molar ratio $(1: 1)$ with different concentrations on the $\mathrm{CV}$ behavior were studied using scan rate of $25 \mathrm{mVs}^{-1}$, the anodic peak current densities $\left(i_{p}{ }^{a}\right)$ increase linearly with the increasing of the monomer and comonomer concentrations as shown in Fig. 3.

This behavior is obvious due to the increased availabil-

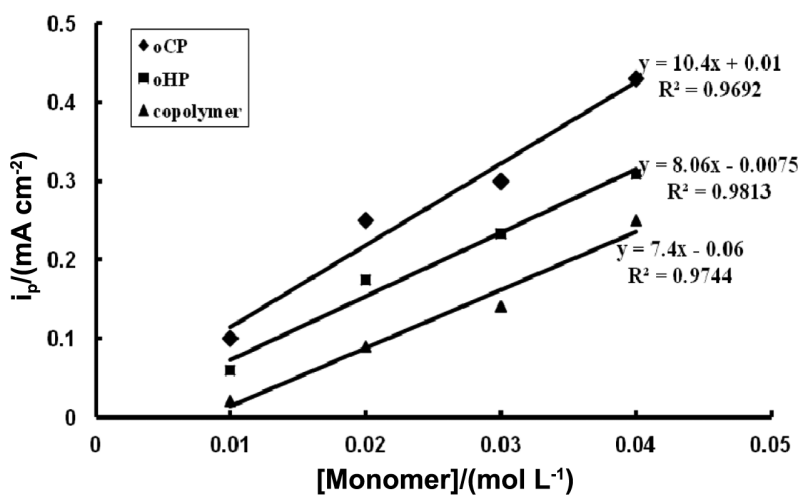

Figure 3. Anodic peak current densities as a function of different phenols concentrations.

ity of the electroactive species in solution and confirms the same nature of the formed homopolymers and copolymer but with different reactivity (linearity equations are different).

This behavior is obvious due to the increased availability of the electroactive species in solution and confirms the same nature of the formed homopolymers and copolymer but with different reactivity (linearity equations are different).

\section{Effect of $\mathrm{H}_{2} \mathrm{SO}_{4}$ concentration}

Fig. 4 represents the influence of acid concentration on the $\mathrm{CV}$ using scan rate of $25 \mathrm{mVs}^{-1}$. The voltammogram shows that, $i_{p}{ }^{a}$ increase linearly with the increasing of the acid concentration. At higher acid concentrations, no noticeable increase in $i_{p}{ }^{a}$ was observed but, it began to decrease as a result of degradation and the solubility of the both homopolymers and copolymer films from the Pt-electrode surface. Also different linearity equations confirm copolymer formation.

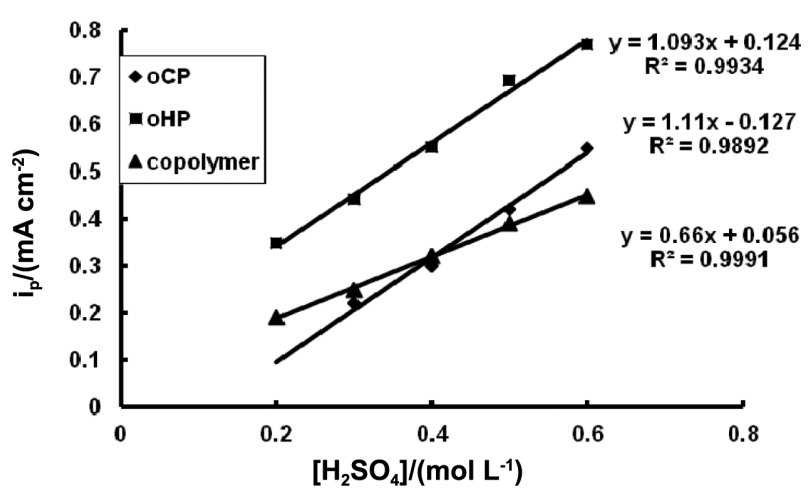

Figure 4. Anodic peak current densities as a function of different $\mathrm{H}_{2} \mathrm{SO}_{4}$ concentrations with different concentrations of phenols (0.08 M oHP, $0.04 \mathrm{M}$ oCP or $0.05 \mathrm{M}$ of oHP and oCP [1:1 molar ratio]. 


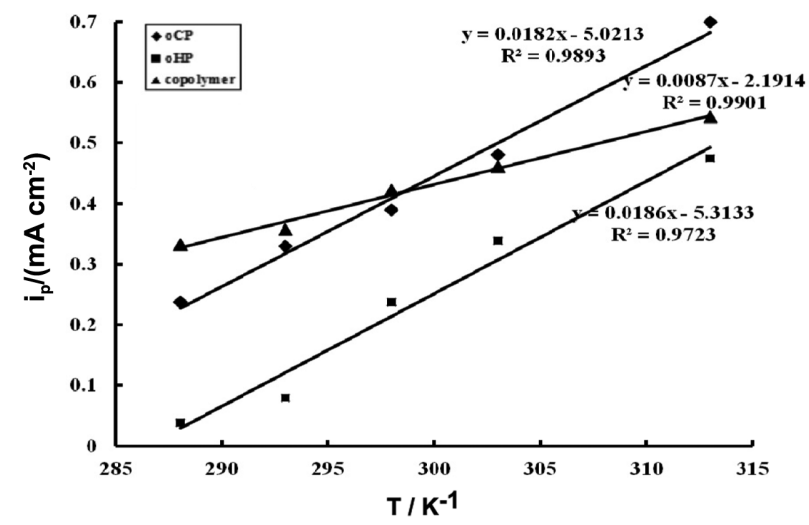

Figure 5. Anodic peak current densities as a function of temperature with different concentrations of phenols $(0.08 \mathrm{M}$ oHP, $0.04 \mathrm{M}$ oCP or $0.05 \mathrm{M}$ of oHP and oCP [1:1 molar ratio].

\section{Effect of temperature}

The potentiodynamic polarization curves as a function of the solution temperature using $25 \mathrm{mVs}^{-1}$ for scan rate were illustrated in Fig. 5. From the Figure, it is clear that, an increase of the reaction temperature resulted in a progressive linear increase in $i_{p}{ }^{a}$ in all cases as a result of increasing the rate of diffusion of phenoxy radicals by increasing solution temperature.

At higher temperatures, no noticeable increase in $i_{p}{ }^{a}$ was observed but, it began to decrease as a result of degradation and the solubility of the both homopolymers and copolymer films from the Pt-electrode surface. Also different linearity equations confirm copolymer formation.

\section{IR Spectroscopy, UV-visible and Elemental Analysis}

The infrared spectra ( $\mathrm{KBr}$ pellets) of homopolymers and copolymer are recorded and shown in Fig. 6. The IR spectra are very complicated. We will briefly assign some main peaks. In the broad peaks centered between 3320 and $3420 \mathrm{~cm}^{-1}$ is due to phenolic $\mathrm{O}-\mathrm{H}$ bond. The peaks between 3046 and $3100 \mathrm{~cm}^{-1}$ are attributed to the aromatic ring C$\mathrm{H}$ stretching vibration. The peaks between 1508 and 1668 $\mathrm{cm}^{-1}$ are attributed to the aromatic ring $\mathrm{C}=\mathrm{C}$ vibration bands. The $\mathrm{C}-\mathrm{O}-\mathrm{C}$ stretching frequency of phenyl ether is also seen at 1250 and $1200 \mathrm{~cm}^{-1}$. ${ }^{43}$ The dopant absorption bands in all cases appearing between 1170 and $1189 \mathrm{~cm}^{-1}$ are attributed to $\mathrm{SO}_{4}{ }^{-2}$ incorporation in the polymeric chain. The peaks between 832 and $857 \mathrm{~cm}^{-1}$ belong to the out-of- plane bending of $=\mathrm{C}-\mathrm{H}$ bonds of an aromatic ring. The peaks at 920 and $900 \mathrm{~cm}^{-1}$ belong to the streching vibration of $\mathrm{C}-\mathrm{Cl}$ bonds in PoCP and $\mathrm{P}(\mathrm{oCP}-\mathrm{co}-\mathrm{oHP})$ respectively. These data indicate that the copolymer contain both homopolymers and its structure is composed of oxyphenylene units and there are still has a phenolic $\mathrm{O}-\mathrm{H}$ functional groups.

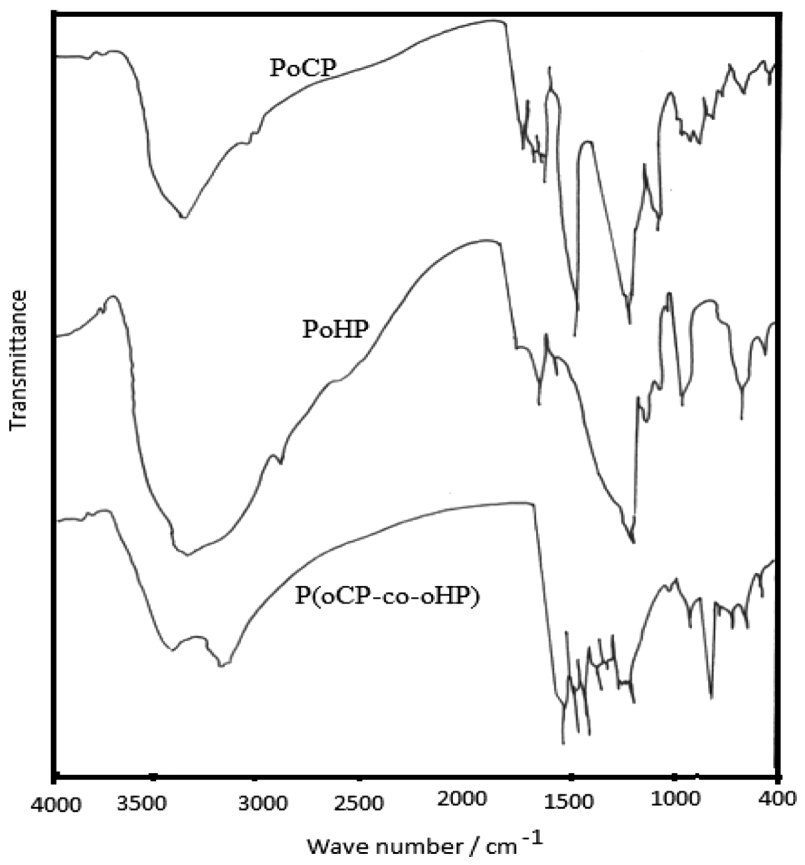

Figure 6. IR spectra of PoHP, PoCP and P (oHP-co-oCP).

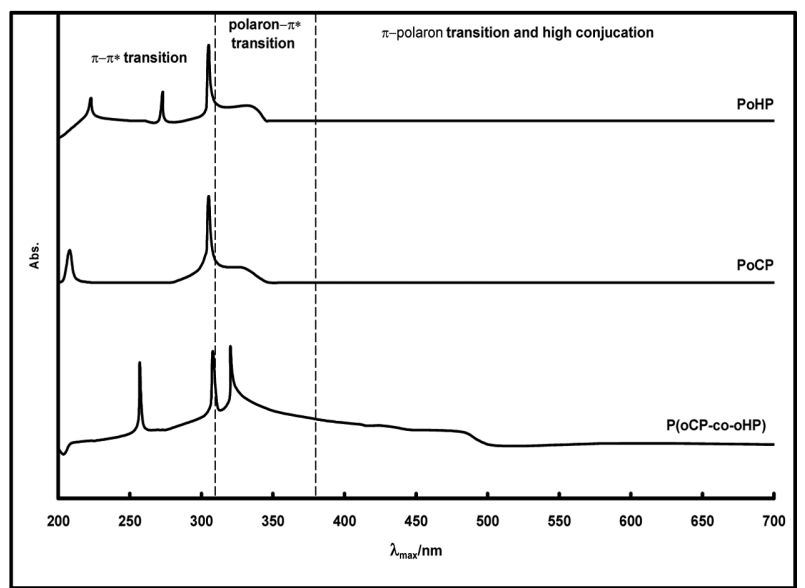

Figure 7. UV-visible spectra of PoHP, PoCP and P (oHP-co-oCP).

The UV-visible spectra of homopolymers (PoHP and PoCP) and copolymer (P (oHP-co-oCP) are shown in Fig. 7. The appearance of a band at $485 \mathrm{~nm}$ for $\pi$-polaron transition ${ }^{41,42}$ in contrast to the spectra of PoCP and PoHP reveals that the copolymer is structurally different and also confirm its formation. This band is attributed to higher conjugation of the coplomer.

Elemental analysis of the obtained copolymer compared with the homopolymers was carried out. The percentage $\mathrm{C}, \mathrm{H}, \mathrm{Cl}$ and $\mathrm{S}$ for all investigated samples are summarized in Table 1. Also, the presence of $(\mathrm{Cl})$ in sample 3 confirms the formation of copolymer. 
Table 1. Elemental analytical data of the prepared homo and copolymer

\begin{tabular}{ccccc}
\hline \multirow{3}{*}{ Samples } & \multicolumn{4}{c}{ Elemental analysis } \\
\cline { 2 - 5 } & $\mathrm{C} \%$ & $\mathrm{H} \%$ & $\mathrm{Cl} \%$ & $\mathrm{~S} \%$ \\
\cline { 2 - 5 } & $\mathrm{Cal} /$ found & $\mathrm{Cal} /$ found & $\mathrm{Cal} /$ found & $\mathrm{Cal} /$ found \\
\hline \multirow{2}{*}{$\mathrm{P}(\mathrm{o}-\mathrm{CP})$} & 47.1 & 2.48 & 23.22 & 4.18 \\
& 47.5 & 2.10 & 23.01 & 4.20 \\
$\mathrm{P}(\mathrm{o}-\mathrm{HP})$ & 55.24 & 3.83 & - & 4.00 \\
& 54.25 & 4.15 & - & 3.48 \\
$\mathrm{P}(\mathrm{oHP}-$ & 52.50 & 3.60 & 11.50 & 2.60 \\
co-oCP) & 51.32 & 4.50 & 11.00 & 3.05 \\
\hline
\end{tabular}

\section{Copolymer Structure and the Mechanism}

The monomer reactivity ratios of the copolymerization system $\left(\mathrm{r}_{1}\right.$ and $\mathrm{r}_{2}$ ) involving oCP and oHP were determined on the basis of comonomer composition-copolymer composition relationship.

The copolymer composition of each sample was calculated according to the chlorine content as follows:

$$
\frac{C l_{\text {content of copolymer }}}{C l_{\text {content of } M_{1}}}=\frac{M w t_{M_{1}}}{M w t_{M_{1}}+M w t_{\left(M_{2} / b\right)}}
$$

Where $M_{1}$ is the chlorine containing monomer oCP and $b=m_{1} / m_{2}$ is the molar ratios of copolymer composition.

The monomer reactivity ratios were calculated according to Fineman-Röss method ${ }^{44}$ using $\mathrm{Cl}$ — content as a quantitative analytical tool.

\section{Fineman-Röss Method}

Both oCP and oHP are incorporated into the copolymer chain depending on their relative concentrations and reactivities. The composition of the copolymer was quantitively determined by $\mathrm{Cl}$-content in the copolymer samples. The monomer reactivity ratios $r_{1}$ and $r_{2}$ of this copolymer was calculated from Fineman-Röss equation ${ }^{44}$ and represented in Fig. 8.

$$
\frac{F}{f(f-1)}=r_{1}\left(\frac{F^{2}}{f}\right)-r_{2}
$$

Where, $F=M_{1} / M_{2}$ (molar ratio for monomer feed composition) and $f=m_{1} / m_{2}$ (molar ratio for copolymer composition).

The slope is equal to $r_{1}$ and the intercept is equal to $-r_{2}$. From the Figure, it was found that $r_{1}=0.4$ and $r_{2}=1.3$.

From the data, the value of $r_{1}$ is less than one and $r_{2}$ is more than one. In this case the propagation type 12 and 22 will be preferred than the type 11 and 21 , hence the probability of $M_{2}$ (oHP) entering into the copolymer chain is higher as compared to $M_{1}$ (oCP), therefore the formed copo-

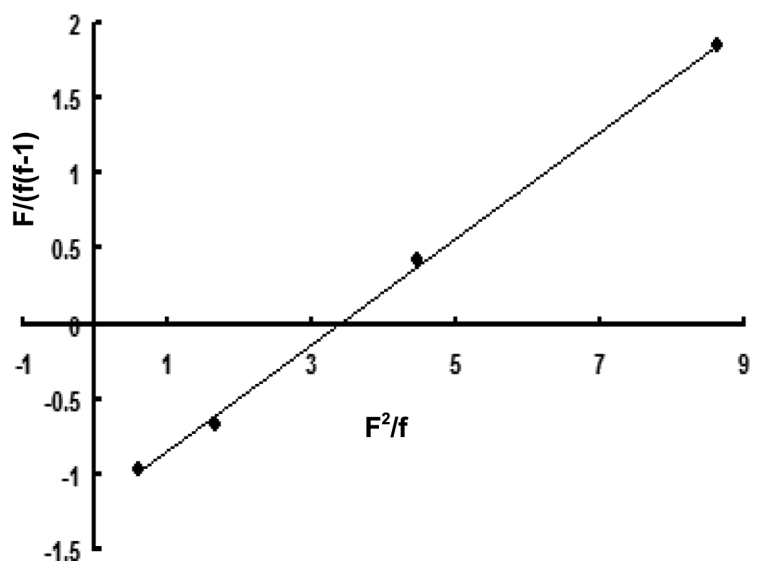

Figure 8. Fineman-Röss plot for the determination of monomer reactivity ratio of o-CP and o-HP in sulfuric acid as supporting electrolyte copolymerized by electrochemical method on Pt-electrode.

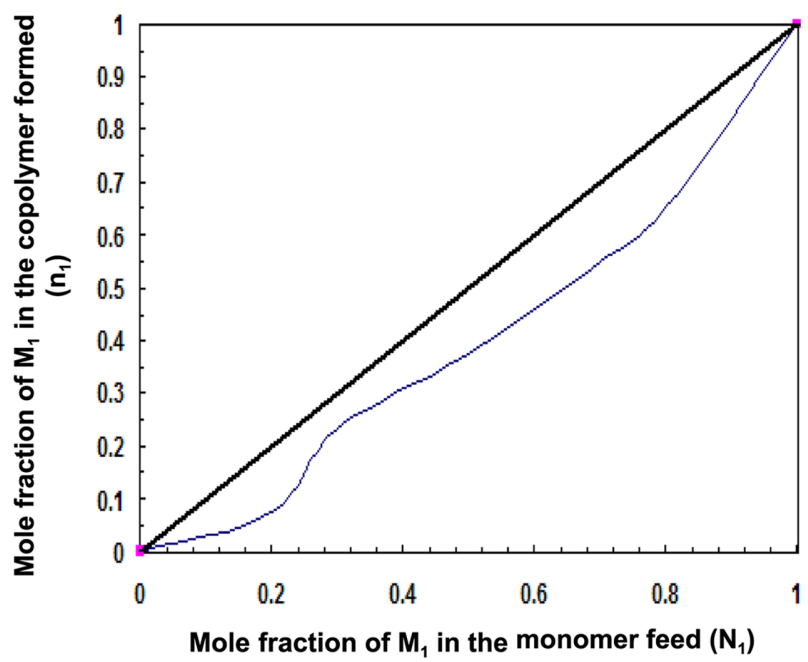

Figure 9. Composition curve between $\mathrm{oCP}\left(M_{1}\right)$ and $\mathrm{oHP}\left(M_{2}\right)$ for the electropolymerization in sulfuric acid solution on Pt electrode.

lymer will be richer in $M_{2}$.

The copolymer composition data for the investigated system were calculated and the relation between the mole fractions of $M_{1}$ in the formed copolymer $\left(n_{1}\right)$ and the mole fraction of $M_{1}$ in monomer feed $\left(N_{1}\right)$ and are represented in Fig. 9.

The diagonal line represents the case that both monomers have identical reactivity. The values of $n_{1}$ for the copolymer are under the diagonal line indicating that the copolymers consist of a higher fraction of oHP units than that of oCP units and that oHP is much more reactive than oCP. From the above data, it is clear that the copolymer structure is a block copolymer structure; therefore the copolymerization mechanism can be represented as shown in Scheme 2. 


\section{Solubility}

Solubility of the copolymer samples is examined in different solvents. The copolymers are partially soluble in DMF and THF and insoluble in solvents like Hexane, chloroform, acetone, methanol, ethanol, DMSO and benzene

\section{CONCLUSION}

Copolymer films could be deposited by polymerizing oCP with oHP using CV methods. The copolymer formation is directly affected by (monomer and acid) concentrations and temperature. The $\mathrm{CV}$ of copolymer differ from that of homopolymers. The oxidation process is a partially diffusion process with $\mathrm{D} \approx 6 \times 10^{-7} \mathrm{~m}^{2} \mathrm{~s}^{-1}$. The appearance of a band at $485 \mathrm{~nm}$ in contrast to the spectra of PoCP and PoHP reveals that the copolymer is structurally different from homopolymers. The copolymer is insoluble in most of used solvents but partially soluble in DMF and THF. Further work will be done to determine the optimum conditions for copolymer formation and also other characterization tools will be used.

Acknowledgments. Publication cost of this paper was supported by the Korean Chemical Society.

\section{REFERENCES}

1. Iniesta, J.; Gonzalez-Garcia, J.; Exposito, E.; Montiel, V.; Aldaz, A. Water Res. 2001, 35/14, 3291.

2. Chettiar, M.; Watkinson, A. P. Can. J. Chem. Eng. 1983, $61,568$.

3. Gattrell, M.; Kirk, D. W. Can. J. Chem. Eng. 1990, 68(6), 997.

4. Wang, J.; Jiang, M.; Lu, F. J. Electroanal. Chem. 1998, 444, 127.

5. Comninellis, Ch.; Pulgarin, C. J. Appl. Electrochem. 1993, 23, 108.

6. Li, X.-Y.; Cui, Y.-H.; Feng, Y.-J.; Xie, Z.-M.; Gu, J.-D. Water Res. 2005, 39, 1972.

7. Iotov, P. I.; Kalcheva, S. V. J. Electroanal. Chem. 1998, 442, 19.

8. Ciriello, R.; Guerrieri, A.; Pavese, F.; Salvi, A. M. Anal. Bioanal. Chem. 2008, 392, 913.

9. Gattrell, M.; Kirk, D. W. J. Electrochem. Soc. 1993, 140(4), 903.

10. Gattrell, M.; Kirk, D. W., J. Electrochem. Soc. 1993, 140(6), 1534.

11. Sayyah, S. M.; Khaliel, A. B.; Azooz, R. E.; Mohamed, F. Electropolymerization; Schab-Balcerzak E., Ed.; InTech: 2011.

12. Belhadj Tahar, N.; Abdelhedi, R.; Savall, A. J. Appl. Electrochem. 2009, 39(5), 663.

13. Panizza, M.; Michaud, P. A.; Cerisola, G.; Comninellis, Ch. J. Electroanal. Chem. 2001, 507, 206.
14. Rodrigo, M. A.; Michaud, P. A.; Duo, I.; Panizza, M.; Cerisola, G.; Comninellis, Ch. J. Electrochem. Soc. 2001, 148(5), D60.

15. Mengoli, G; Daolio, S.; Musiani, M. M. J. Appl. Electrochem. 1980, 10(4), 459.

16. Mengoli, G.; Musiani, M. M. Electrochim. Acta 1986, 31/ 2, 201.

17. Papouchado, L.; Sandford, R. W.; Petrie, G.; Adams, R. N. J. Electroanal. Chem. 1975, 65, 275.

18. Bruno, F.; Pham, M. C.; Dubois, J. E. Electrochim. Acta 1977, 22(4), 451.

19. Panizza, M.; Cerisola, G. Electrochim. Acta 2003, 48(23), 3491.

20. Vermillion, F. J.; Pearl, I. A. J. Electrochem. Soc. 1964, 111(12), 1392.

21. Gattrell, M.; MacDougall, B. J. Electrochem. Soc. 1999, 146(9), 3335.

22. Ezerskis, Z.; Jusys, Z. J. Appl. Electrochem. 2001, 31(10), 1117.

23. Gattrell, M.; Kirk, D. W. J. Electrochem. Soc. 1992, 139(10), 2736.

24. Koile, R. C.; Johnson, D. C. Anal. Chem. 1979, 51(6), 741.

25. Babai, M.; Gottesfeld, S. Surf. Sci. 1980, 96, 461.

26. Kuramitz, H.; Nakata, Y.; Kawasaki, M.; Tanaka, S. Chemosphere 2001, 45, 37.

27. Kuramitz, H.; Saitoh, J.; Hattori, T.; Tanaka, S. Water Res. 2002, 36, 3323.

28. Kuramitz, H.; Matsushita, M.; Tanaka, S. Water Res. 2004, $38,2330$.

29. Sayyah, S. M.; Abd El-Rehim, S. S.; El-Deeb, M. M.; Kamal, S. M.; Azooz. R. E. J. Appl Polym Sci. 2010, 117(2), 943.

30. Andreescu, S.; Andreescu, D.; Sadik, O. A. Electrochem. Commun. 2003, 5, 681.

31. Arslan, G.; Yazici, B.; Erbil, M. J. Hazard. Mat. 2005, B124, 37.

32. Mahanta, D.; Madrus, G.; Radhakrishnan, S.; Pati, S. Phys. Chem. 2009, B113, 2293.

33. Scholz, F.; Schadel, S.; Schultz, A.; Schauer, F. J. Electroan. Chem. 2000, 480, 241.

34. Sayyah, S. M.; El-Deeb, M. M.; Kamal, S. M.; Azooz, R. E. J. Appl. Polym. Sci. 2009, 112(6), 3695.

35. Randles, J. E. B. Trans. Faraday Soc. 1948, 44, 327.

36. Sevick, A. Collect. Czech. Chem. Commun. 1948, 13, 349.

37. Sayyah, S. M.; El-deeb, M. M. J. Appl. Polym. Sci. 2007, 103(6), 4047.

38. Ardakani, M. M.; Sadeghiane, A.; Moosavizadeh, S.; Karimi, M. A.; Mashhadizadeh, M. H. Anal. Bioanal. Electrochem. 2009, 1(3), 224.

39. Nicholson, R. S. Anal. Chem. 1965, 37, 1351.

40. Ureta-Zanatru, M. S.; bustos, P.; Berrios, C.; Diez, M. C.; Mora, M. L.; Gutierrez, C. Electrochim. Acta 2002, 47, 2399.

41. Abd El Rehim, S. S.; Sayyah S. M.; Azooz, R. E. Port. Electrochim. Acta 2012, 30(1), 67.

42. Sayyah, S. M.; Abd El-Rehim, S. S.; Kamal, S. M.; El-Deeb, M. M.; Azooz R. E. J. Appl. Poly. Sci. 2011, 119, 252.

43. Dubey, S.; Singh, D.; Misra, R. A. Enzyme Microbiol. Technol. 1998, 23, 432.

44. Finman, M.; Ross, S. D. Polymer Sci. 1950, 5, 259. 